\title{
Resilience and Treatment Adhesion in Patients with Systemic Lupus Erythematosus
}

\author{
Daniella Antunes Pousa Faria ${ }^{*}, 1$, Luciana Silva Revoredo ${ }^{1}$, Maria José Vilar ${ }^{1}$ and \\ Eulália Maria Chaves Maia ${ }^{1,2}$
}

\author{
${ }^{I}$ Programa de Pós-Graduação em Ciências da Saúde, Universidade Federal do Rio Grande do Norte (UFRN), Natal, \\ Brazil \\ ${ }^{2}$ Programa de Pós-Graduação em Psicologia, Universidade Federal do Rio Grande do Norte, Natal, Brazil
}

\begin{abstract}
Background: Systemic Lupus Erythematosus (SLE) is a chronic autoimmune, rheumatic inflammatory disease that can cause significant morbidity with evident psychological impacts and obvious harm to quality-of-life that require the patient to adapt treatment.

Objective: Assessment of resilience and the self-reported treatment adhesion behaviors of patients with SLE, investigating which of these factors are associated to resilience.

Method: Cross-sectional study of 40 women with SLE. A questionnaire with social demographic data, health history and the Wagnild Young Resilience Scale were used.

Results: $62.5 \%$ followed the medical treatment properly but $55 \%$ found it difficult. $27.5 \%$ of the patients presented low resilience, $57.5 \%$ medium and $15 \%$ high resilience. Resilience was associated in the chi-square test $(\mathrm{p}$-value $<0.05)$ with the variables work, understanding SLE, trying to find out about SLE, following the treatment correctly, difficulty in following the treatment and stopping some activity because of the disease. In the correlation analysis, resilience was associated with age $(-0.3960)$, number of working hours $(0.5533)$, specialized treatment duration $(-0.8103)$ and disease duration from diagnosis $(-0.8014)$.

Conclusion: Patients with high resilience tended to follow treatment correctly, tried to understand the disease and adhered more to the treatment to avoid risks and promote protection factors. Therefore knowledge of resilience in patients with SLE is necessary. It is important that the state takes necessary actions to facilitate access to treatment, to educational programs and to medical support. Awareness and counselling sessions must be initiated to develop and promote individual capacities to learn how to tackle with the disease for which psychological support of family and doctors can play a significant role.
\end{abstract}

Keywords: Resilience, treatment adhesion, systemic lupus erythematosus.

\section{INTRODUCTION}

Systemic Lupus Erythematosus (SLE) is a chronic autoimmune, rheumatic inflammatory disease that can affect several organs and systems in the body, causing significant morbidity [1-3] with evident psychological impacts $[3,4]$ such as anxiety and depression $[5,6]$ and obvious harm to life satisfaction [3] and quality-of-life [7,8] that require the patient to adapt treatment and the situation of living with a chronic disease. It is more common in young persons, especially women [3]. The incidence of SLE in Natal $\mathrm{RN} /$ Brazil is apparently higher than those reported in other regions of the world, 8.7/100 000/year [9].

*Address correspondence to this author at the UFRN Programa de Pósgraduação em Ciências da Saúde, Tereza Campos, 2070, apto, 601, Lagoa Nova, CEP 59062-530. Natal, Rio Grande do Norte. Brazil;

Tel: (+55)8433429776; Fax: (+55)8433429776;

E-mail: daniellapousa@gmail.com
In this context, it is important to introduce the concept of resilience: it is an unfixed, universal capacity, that can be triggered and disappear at certain times of life [10-13], and allows the subject to prevent, minimize or overcome noxious effects of adversities, and that even if not unscathed, he/she can come out strengthened or transformed from these situations [10-12]. Resilience further involves risk factors that refer to every event that is an obstacle at the individual or environmental level and that enhance the individual's vulnerability to negative developmental results while protection includes factors with potential capacity to minimize the possible negative or dysfunctional effects in the presence of the risk [13].

Disease-related resilience can be understood as the capacity of an individual to deal with the disease, accepting his/her limitations, collaborating by adhering to the treatment, readapting and surviving positively [14]. Diseaserelated resilience can be thought as the risk and protection factors and in the present study adhesion to treatment was 
understood as an important protection behavior for diseaserelated resilience and non-adherence as a risk factor, because not following the treatment could worsen the disease [15].

Therefore in SLE, risk is considered, in this study, nonadhesion to the treatment that includes: not following the medication and suggested treatments, not knowing about the disease, not accepting its limitations, and not following medical recommendations (regular visits to the physician, no smoking, avoiding sunlight and controlling heart disease risk). Adhesion to the treatment and having a support network are considered as protection factors. Thus when dealing with resilience in the situation of living with a chronic disease such as SLE, adhesion to the treatment is a central issue.

Thus the objective of the present study was to assess resilience and treatment adhesion behaviors reported by patients with SLE, investigating which of these factors were associated with resilience.

\section{MATERIALS AND METHODOLOGY}

Cross-sectional study, descriptive and exploratory purpose, with patients diagnosed for SLE.

\section{Population Studied}

Forty female patients over 18 took part, diagnosed for SLE, from the Rheumatology Outpatients Department of the Onofre Lopes Hospital (HUOL), Natal/RN - Brazil, who agreed to participate in the research. The data were collected from March 2010 to January 2011, after approval from the Ethics Committee; research number 066/09, at the Federal University of Rio Grande do Norte, Brazil. This research followed the norms established by the Helsinki Declaration of 1975 , as revised in 2008.

The total sample was obtained using The Single Random Sample, with $95 \%$ confidence interval. The inclusion criteria were: the patients were in treatment at the HOUL Rheumatology Outpatients Department, diagnosed for SLE and over 18, without clinical conditions that in the opinion of the physician, could damage participation in the investigation, and no record of neuropsychiatric disorders.

\section{Instruments Used}

A questionnaire was administered with social and demographic data, health aspects and history (disease data, diagnosis and support network data, treatment data, treatment adhesion behaviors, disease impact data, risk and protection factors and data on the patient's daily life) elaborated based on information contained in the Systemic Lupus Erythematosus Consensus [16]. The Resilience Scale developed by Wagnild \& Young [17] was used that measures the levels of positive psychological adaptation to important life events where 25 items are described positively with a likert type response ranging from 1 (disagree completely) to 7 (agree completely). The scale scores range from 25 to 175 points and high values indicate high resilience. This is a valid and reliable instrument that has been translated into Portuguese [18].

\section{Methodological Procedures}

Rheumatologists were contacted to identify patients diagnosed with SLE that met the inclusion criteria and the research objectives were explained to these patients. On their approval to participate, the patients were made to sign a free consent term. The questionnaire was then administered, followed by the Wagnild \& Young Resilience Scale [17]. The procedure took approximately 40 minutes.

\section{Data Analysis}

The Statistic program, version 6.0, was used to analyze the data. Descriptive statistics were used to describe the profile of the patients analyzed and characterize the disease and disease-induced behavior. The chi-squared test was applied to verify whether there was association between the resilience variable and the categorical variables involved in the study (work, SLE understanding, attempt to find out about SLE, followed the treatment correctly, difficulty in following the treatment, stopped activity because of SLE, education, family income, understanding of SLE care, understanding the treatment, medical attention frequency, smoking, heart disease risk control which includes hypertension, obesity, dyslipidemia and glucose control [16], extra medication treatment, received support, government assistance, facilitated access to consultation, facilitated access to tests and facilitated access to medication). Correlation analysis was applied to verify whether there was association between resilience and the quantitative variables listed below involved in the study (age, number of working hours, when the physician was consulted after first symptoms appear, time taken for diagnosis after seeking the physician, specialized treatment duration and disease duration from diagnosis).

The level of significance adopted in the cases was 5\% (pvalue $<0.05)$. The Resilience Scale was corrected by the manual. For this study, resilience was considered as: 25-75= low resilience, 76-125 = medium and $126-175-$ high resilience [12].

\section{RESULTS}

Table 1 shows the profile of the patients analyzed.

According to the above table, $32.5 \%$ of the patients were in the 42 to 48 -year-old age group, $52.5 \%$ were married, $50 \%$ had only primary education, $65 \%$ had $1-3$ minimum wage family income and only $17.5 \%$ worked outside the home.

The patients had SLE for an average of $6.88 \pm 5.39$ years duration, mean 5.0 years. The patients reported that after getting medical help they took on average $7.58 \pm 9.66$ months to discover the diagnosis, mean 3.0 months. The average treatment duration of these patients was $6.47 \pm 4.93$ years, mean 5.0 years.

Of the patients assessed, $87.5 \%$ reported giving up some activity because of SLE: $77.1 \%$ stopped working, $14.3 \%$ stopped doing housework and $8.6 \%$ stopped leisure activities. The patients reported the following reasons for giving up these activities: pain (54.3\%), fatigue (28.5\%), 
Table 1. Social and Demographic Profile of the Study Sample

\begin{tabular}{|c|c|c|}
\hline Characteristics & $\mathbf{N}$ & $\%$ \\
\hline \multicolumn{3}{|l|}{ Age Group in Years } \\
\hline 21 to 27 & 8 & 20.0 \\
\hline 28 to 34 & 9 & 22.5 \\
\hline 35 to 41 & 3 & 7.5 \\
\hline 42 to 48 & 13 & 32.5 \\
\hline 49 to 55 & 4 & 10.0 \\
\hline 56 to 62 & 3 & 7.5 \\
\hline \multicolumn{3}{|l|}{ Civil State } \\
\hline Single & 14 & 35.0 \\
\hline Married & 21 & 52.5 \\
\hline Divorced & 4 & 10.0 \\
\hline Other & 1 & 2.5 \\
\hline \multicolumn{3}{|l|}{ Education } \\
\hline Primary & 20 & 50 \\
\hline High School & 15 & 37.5 \\
\hline University & 1 & 2.5 \\
\hline University unfinished & 4 & 10.0 \\
\hline \multicolumn{3}{|l|}{ Work Outside Home } \\
\hline No & 33 & 82.5 \\
\hline Yes & 7 & 17.5 \\
\hline \multicolumn{3}{|l|}{ Working Hours } \\
\hline Does not work & 33 & 82.5 \\
\hline 20 hours & 5 & 12.5 \\
\hline 40 hours & 2 & 5.0 \\
\hline \multicolumn{3}{|c|}{ Family Income (in Minimum Wage) } \\
\hline Less than 1 m.w. & 10 & 25.0 \\
\hline From 1 to $3 \mathrm{~m} . \mathrm{w}$. & 26 & 65.0 \\
\hline From 4 to 6 m.w. & 3 & 7.5 \\
\hline From 7 to 9 m.w. & 1 & 2.5 \\
\hline
\end{tabular}

symptoms of depression (8.6\%) and disease activity $(8.6 \%)$. The pain reported by $65.5 \%$ of the patients was the symptom that distressed them most.

Resilience involves risk and protection factors; in the case of SLE risk is considered non-adhesion to the treatment and protection is adhesion to the treatment. The patients were asked some questions to understand their reports of the characteristics of adhesion to the treatment, using as reference the general means highlighted as important in the therapeutic approach of the Systemic Lupus Erythematosus Consensus [16] and the results are shown in Table 2.

The medication treatment was carried out properly by $62.5 \%$ of the patients and only $2.5 \%$ did not visit the physician regularly. Most followed the recommendations not to smoke, $(90 \%)$, avoid sunlight $(100 \%)$ and control heart disease (90\%). However, 55\% reported difficulty in following the medication treatment because the medication was not available from the SUS - Single Health System (Sistema Único de Saúde) (54.5\%) and forgetfulness $(36.4 \%)$. The SUS is the public health care system that ensures access to whole, universal and free health care for the Brazilian population; 9.1\% did not know how to answer the reason for difficulty.

Table 2. Risk and Protection Factors Assessed of 40 Patients with SLE

\begin{tabular}{|l|c|c|}
\hline \multicolumn{1}{|c|}{ Characteristics } & N & \% \\
\hline \hline Follow Medication Treatment Correctly \\
\hline No & 15 & 37.5 \\
\hline Yes & 25 & 62.5 \\
\hline Frequency of Visits to Physician & 12 & 30.0 \\
\hline Monthly & 6 & 15.0 \\
\hline Every 2 months & 18 & 45.0 \\
\hline Every 3 months & 3 & 7.5 \\
\hline Every 6 months & 1 & 2.5 \\
\hline No regular visits & 36 & 90.0 \\
\hline Smoking & 4 & 10.0 \\
\hline No & 4 & 10.0 \\
\hline Yes & 36 & 90.0 \\
\hline Avoiding Sunlight & \multicolumn{2}{|}{} \\
\hline Yes & \multicolumn{2}{|c|}{} \\
\hline $\begin{array}{l}\text { Control of Heart Disease Risk } \\
\text { (Hypertension, Obesity, Dyslipidemia and Glucose Control) }\end{array}$ \\
\hline No & 400.0 \\
\hline Yes & \multicolumn{2}{|c|}{} \\
\hline
\end{tabular}

Of the patients assessed, $32.5 \%$ stated that they did not understand SLE, $42.5 \%$ partly understood it and $25 \%$ stated they understood the disease regarding self-care, $60 \%$ stated they understood the self-care they should take because of the disease, $37.55 \%$ partly understood and $2.5 \%$ did not know what care they should take. Regarding understanding the treatments, $60.5 \%$ declared that they understood the treatments and $37.5 \%$ partly understood. In addition, $42.5 \%$ stated that they did not look for information on SLE other than that given by the physician, 57.5\% looked for information on SLE in addition to what was said by the physician.

Regarding the support network perceived by the patients, $82.5 \%$ of the patients stated they received support and $72.5 \%$ felt supported by their family. Table 3 shows the results regarding the government support network.

It was observed that $52.5 \%$ of the patients did not feel helped by the government because $65 \%$ stated they had no facilitated access to consultations, $82.5 \%$ did not have facilitated access to the tests and $67.5 \%$ did not have facilitated access to medication. In Brazil the appointments 
Table 3. Description of the Government Support Network

\begin{tabular}{|c|c|c|}
\hline Characteristics & $\mathbf{N}$ & $\%$ \\
\hline \multicolumn{3}{|l|}{ Felt Helped by the Government } \\
\hline No & 21 & 52.5 \\
\hline Yes & 19 & 47.5 \\
\hline \multicolumn{3}{|l|}{ Facilitated Access to Consultation } \\
\hline No & 26 & 65.0 \\
\hline Yes & 14 & 35.0 \\
\hline \multicolumn{3}{|l|}{ Facilitated Access to Tests } \\
\hline No & 33 & 82.5 \\
\hline Yes & 7 & 17.5 \\
\hline \multicolumn{3}{|l|}{ Facilitated Access to Medication } \\
\hline No & 27 & 67.5 \\
\hline Yes & 13 & 32.5 \\
\hline \multicolumn{3}{|l|}{ Medication acquisition } \\
\hline Bought & 16 & 40.0 \\
\hline Bought by members of the family & 3 & 7.5 \\
\hline Received from the Government & 10 & 25.0 \\
\hline Bought and received through the government & 10 & 25.0 \\
\hline Bought and received from the government & 1 & 2.5 \\
\hline \multicolumn{3}{|c|}{ Participation in Psychological Help Support Groups } \\
\hline No & 40 & 100 \\
\hline
\end{tabular}

and tests are free of charge through the Single Health System, called SUS. This health system is financed by the state. But not always patients seeking SUS services can receive medical care due to the large number of patients and lack of professionals to serve them. Furthermore, no patient participated in a support group or had psychological help.

$27.5 \%$ of the patients presented low resilience, $57.5 \%$ medium resilience and around $15 \%$ presented high resilience. Table 4 shows that patients presented a mean resilience of 99.83 \pm 27.70 points, average of 106.50 . These results were categorized as medium resilience [12].

The chi square and Pearson tests were applied in order to identify which of the variables analyzed had to be associated with resilience. Only six of the 19 variables analyzed were associated with resilience ( $p$-valor $<0.05)$. Therefore resilience was associated with the variables work, giving up some activity because of SLE, following the treatment properly, the difficulty in following the treatment, trying to know more about lupus and understanding lupus, at the level of 5\% significance (Table 5).
The results indicated that the patients that worked tended to present high resilience, while those that did not work presented low resilience. None of the patients with low resilience worked outside the home. $91 \%$ of the patients with medium resilience did not work, and those that had high resilience corresponded to $83 \%$ of the patients that worked.

Patients who stopped some activity because of SLE tended to present low resilience while those that did not, tended to present high resilience. The patients with low resilience had stopped some activity because of SLE. Among those with high resilience, $83 \%$ were the patients who did not stop any activity due to SLE.

The patients who carried out the medication treatment correctly tended to present high resilience, while those that did not tended to present low resilience. $91 \%$ of patients with low resilience were patients that did not follow the medication treatment correctly. Among those that had medium resilience $78 \%$ followed the treatment correctly, while all those with high resilience followed the medication treatment properly. Furthermore the patients who found it difficult to follow the treatment tended to present low resilience, while those that did not tended to present high resilience levels. All the patients that found it difficult to follow the treatment had low resilience. Among those with medium resilience $52 \%$ did not find it difficult to follow the treatment and those with high resilience were all the patients that did not find it difficult to follow the treatment.

The patients that understood SLE tended to present high resilience, while those who did not tended to present low resilience. $64 \%$ of the patients with low resilience were the patients who did not understand SLE. Among those with medium resilience, $52 \%$ understood in part, and those with high resilience corresponded to $83 \%$ of the patients who understood SLE.

Patients who tried to find out about SLE, who looked for information on the disease in addition to that given by the physicians, tended to high resilience, while patients who did not tended to present low resilience. $73 \%$ of the patients with low resilience were the patients that did not try to find out about SLE. $39 \%$ of the patients with medium resilience did not try to find out about SLE and those with high resilience corresponded to $83 \%$ of patients that tried to find out about SLE.

The correlation test showed that resilience was associated with 04 of the variables analyzed, at 5\% level of significance (p-value $<0.05$ ), shown in Table 6.

There was low and negative correlation between resilience and age, $-0.3960(39.6 \%)$ : as age increased resilience decreased. There was a positive and moderate correlation between resilience and working hours, 0.5533 $(55.33 \%)$ : as the number of hours worked increased

Table 4. Resilience Values Achieved by Patients Evaluated

\begin{tabular}{|c|c|c|c|c|c|c|}
\hline \multirow{2}{*}{ Variables } & \multicolumn{2}{|c|}{ Value Absolute } & \multirow{2}{*}{ Mean \pm DP } & \multirow{2}{*}{ Average } & \multicolumn{2}{|c|}{ Confidence Interval (95\%) } \\
\hline & Minimum & Maximum & & & Minimum & Maximum \\
\hline Resilience & 51.00 & 158.00 & $99.83 \pm 27.70$ & 106.50 & 90.97 & 108.68 \\
\hline
\end{tabular}


Table 5. Pearson Test Chi-Square for the Resilience Classification Variable

\begin{tabular}{|l|l|}
\hline Pearson Chi-Square Analysis of Association & $\mathbf{p}$-Value \\
\hline \hline Resilience $\times$ Work & $\mathbf{p}=\mathbf{0 . 0 0 0 0 2}$ \\
\hline Resilience $\times$ giving up activity because of SLE & $\mathbf{p}=\mathbf{0 . 0 0 0 0 0}$ \\
\hline Resilience $\times$ following treatment correctly & $\mathbf{p}=\mathbf{0 . 0 0 0 0 6}$ \\
\hline Resilience $\times$ Difficulty in following the treatment & $\mathbf{p}=\mathbf{0 . 0 0 0 2 2}$ \\
\hline Resilience $\times$ Found out about SLE & $\mathbf{p}=\mathbf{0 . 0 0 6 4 1}$ \\
\hline Resilience $\times$ Understanding SLE & $\mathbf{p}=\mathbf{0 . 0 0 1 1 9}$ \\
\hline Resilience $\times$ Education & $\mathrm{p}=0.15114$ \\
\hline Resilience $\times$ Family income & $\mathrm{p}=0.38561$ \\
\hline Resilience $\times$ Understanding care of SLE & $\mathrm{p}=0.43320$ \\
\hline Resilience $\times$ Understanding treatment & $\mathrm{p}=0.26602$ \\
\hline Resilience $\times$ Frequency of visiting the physician & $\mathrm{p}=0.80272$ \\
\hline Resilience $\times$ Smoking & $\mathrm{p}=0.46573$ \\
\hline Resilience $\times$ Control of heart disease risk & $\mathrm{p}=0.63335$ \\
\hline Resilience $\times$ Extra-medication treatment & $\mathrm{p}=0.30162$ \\
\hline Resilience $\times$ Receiving support & $\mathrm{p}=0.99670$ \\
\hline Resilience $\times$ Government assistance & $\mathrm{p}=0.98291$ \\
\hline Resilience $\times$ Facilitated access to consultations & $\mathrm{p}=0.58628$ \\
\hline Resilience $\times$ Facilitated access to tests & $\mathrm{p}=0.36778$ \\
\hline Resilience $\times$ Facilitated access to medication & $\mathrm{p}=0.94107$ \\
\hline
\end{tabular}

Table 6. Analysis of Resilience Correlation

\begin{tabular}{|l|r|}
\hline \multicolumn{1}{|c|}{ Correlation } & Resilience \\
\hline \hline Age & $\mathbf{- 0 . 3 9 6 0}$ \\
\hline Number of working hours & $\mathbf{0 . 5 5 3 3}$ \\
\hline When the physician was consulted after first symptoms appear & 0.2084 \\
\hline Time taken for diagnosis after seeking the physician & 0.0666 \\
\hline Specialized treatment duration & $\mathbf{- 0 . 8 1 0 3}$ \\
\hline Disease duration from diagnosis & $\mathbf{- 0 . 8 0 1 4}$ \\
\hline
\end{tabular}

resilience also increased. There was a negative and high correlation between resilience and disease duration from diagnosis, $-0.8014(80.14 \%)$ : as disease duration increased, resilience decreased. There was strong and negative correlation between resilience and specialized treatment duration, $-0.8103(81.03 \%)$ : as treatment duration increased resilience decreased.

\section{DISCUSSION}

The patients assessed were in an age group where people are normally in full working activity, but in the population investigated most had stopped working due to SLE. Furthermore, the patients had stopped doing housework and leisure activities because of fatigue, depression symptoms, disease activity and pain and the latter was the most distressing. These symptoms are also described in the literature as being associated to incapacity for work $[2,19$ 21].

Many of the SLE symptoms interfered in several areas of the patient's life [22] and consequently in their quality of life $[7,8]$ and consequences can include giving up regular work $[2,19,21]$ and daily activities, as the results above show. Nevertheless, resilience can be a contributing factor so that these patients can change their lifestyle but maintain their activities as far as possible because resilience is successful adaptation in spite of adversity or stress and implies efficacious performance of daily activities [12,13, 23].

The association found between resilience and work and the association found between resilience and stopping some activity because of the disease, corroborated with the statement that high resilience helps the subject overcome difficulties that he/she may find in life [11] tending to maintain their activities as far as possible even in adversity, in the case of SLE. The correlation analysis corroborated these statements showing a moderate and positive correlation between resilience and working hours, because resilience also tended to increase as the number of working hours increased. This result strengthens the discussion that patients with high resilience tend to be adapted to the adverse situation [11-13] and continue work and activities, even with the limitations of the disease.

Most of the patients in the present study had medium resilience, this result was similar to a study that aimed to assess the resilience in forty-five patients with SLE, in which the majority $(71 \%)$ had scores in the average levels of resilience [23], that means that they were managing to adapt to the disease to avoid risks and to promote protection factors that contributed to treatment adhesion. Thus, resilience could be understood as a contributor to protective effect [23], and high scores are associated with better physical health, fewer symptoms and a better quality of life while low scores are inversely related to depression and other psychiatric disorders [24].

Treatment adhesion in SLE is a determinant factor in preventing disease activity and not taking the medication is an important cause of non-adhesion [25]. Difficulty in following the treatment has been reported in various studies [25-27] where forgetting the medication $[25,26]$ is highlighted as a non-adhesion cause, along with carelessness with set times to take the medication, adverse reactions to the main ingredient and interrupting the treatment because the symptoms improve [26]. In the present study, most of the patients followed the medication treatment correctly especially patients with high resilience, where resilience was associated to the variable following the medication treatment correctly. Most patients with low resilience tended to not follow the medication treatment correctly. Thus it was observed that high resilience allows patients to have an active posture towards the disease, following the medical recommendations and following the medication treatment correctly, which is essential behavior for adhesion to the treatment [25]. However, the analysis showed that most patients reported difficulty in following it, showing an association between resilience and difficulty in following the treatment: patients who tended to find difficulty were those 
with low resilience. The patients that did not find it difficult tended to present high resilience.

Forgetfulness was reported as one of the difficulties, but the main cause indicated was that the medication was not available from the SUS. The population investigated in the present study depended on government assistance to carry out treatment and was predominantly from the lower economic class. The government provided the medication free, but in practice it was frequently not available at the points of delivery. Thus most patients did not feel helped by the government because they did not have facilitated access to consultation, tests and medication, the factors that prevented these patients from adhering to the treatment.

Furthermore, no patient had access to support groups or psychological treatment. The support the patients stated to have was usually from the family, because they could not have access to psychological treatment and support groups via the SUS, which is a matter of concern because psychological manifestations such as depression $[4,5,28]$, mood disturbance and anxiety $[28,29]$ are common in patients with SLE and require specialized psychological support.

The measures for protection factors were mostly followed by the patients, because most carried out the medication treatment and recommendations correctly such as not smoking, avoiding sunlight, systematic heart disease control, and visiting the physician regularly. Following the medical recommendations and the treatment properly are significant factors for treatment adhesion [26,27] and for understanding disease-linked resilience, because these adhesion behaviors indicate that the patient is managing to be resilient adapting to the adversity of having a chronic disease, accepting limitations, managing to overcome these limitations positively, not necessarily unscathed, but managing to adhere to the treatment.

Trying to understand the disease was also an important factor for treatment adhesion. Most of the patients assessed stated they understood at least in part the disease and most also stated that they understand the self-care. But few looked information on SLE, besides what was said by the physician that can be justified by their low education level, most patients had only primary education. However, there was association between resilience and understanding SLE and resilience and trying to find out about SLE, in addition to the information given by the physician; that is, the patients who understood SLE tended to present high resilience, and those that did not understand tended to present low resilience; patients that tried to find out about SLE also tended to present high resilience and those that did not, tended to present low resilience.

Awareness of the disease is an important factor for treatment adhesion [30] because even the most active patients, when they were not properly informed and did not establish a link with the health service, were more likely not to accept the treatment suggested [30]. Those that accepted the treatment, making it part of their daily routine, no longer perceived as an obligation [30]. Another study investigated the relationship between representations of the disease and depression in lupus patients and reported a perception of the disease as having negative, unpredictable life consequences and patients with little understanding of lupus presented high depression levels [5]. Therefore understanding the disease is an important factor even for the psychological health of the patient.

Age had low and negative correlation with resilience; as age increased, resilience tended to decrease. But as the correlation was low, this result should be further investigated because there are few reports on resilience and age in the literature. However, research on resilience and its relationship with age and sex in 1.719 Swedish participants aged 19-103 showed that resilience was related to age [31] and the older individuals presented high resilience indices, contrary to the results of the present study.

Negative correlation between resilience and disease duration from diagnosis meant that as the disease duration increased resilience decreased and a strong and negative correlation between resilience and specialized treatment duration, meant that as treatment duration increased, resilience decreased, highlighting the issue that SLE is an unpredictable disease with fluctuating disease activity [21] and requires long-term treatment, and patients have to live with medication side-effects and the damage caused by the disease itself, that often results in reduced quality-of-life for the patient [22]. These aspects can discourage the patient, reducing the adaptation capacity and can further lead to dissatisfaction with life that interferes in resilience.

In this context, it is important to think about ways to promote resilience in patients with SLE because resilience has been described as one of important factors to achieve better treatment and health outcomes in patients with SLE [15]. To promote resilience, interventions are necessary in the environmental or external aspects, psychosocial and internal aspects of the subject [32], involving the articulation of the risk and protection factors $[11,32,33]$.

An important factor that can contribute to promoting resilience in the population studied is a reorganization of certain external, psychological and social factors. Actions are required from the state to improve issues related to the situation of risks to the health of patients with SLE, for example, greater effectiveness in medication delivery and facilitated access to consultations and examinations to facilitate the adhesion to the treatment, especially for the population studied, that has little education and depends directly on the public health service. Furthermore, to promote resilience education also should be considered [15]. Assistance institutions should act to promote school education and educative actions for these patients because, as can be observed in the results, few patients really understand SLE, which is a determining factor for adhering to the treatment [15,30] and promoting resilience [15]. Understanding the disease the patients probably will be able to have a greater self-care, avoiding risk factors linked to the disease, such as exposure to the sun and smoking but taking protective measure such as, taking the medication correctly and frequent medical visits to control the disease.

Regarding the psychological and social factors, the support from the physician and the certainty that this professional is someone the patient can trust have been described as important for overcoming the disease in chronic cancer [32] and SLE [15]. The incentive and encouragement 
they received from the family and their friends $[15,32]$ have also been shown as factors that allow patients to feel more motivated to persevere and deal better with the disease [15].

As medical support is shown as important to overcoming the processes linked to the disease [15], there is a need for professionals and assistance institutions to implant a more friendly assistance service, offering information for patients about the disease, ways of caring and treatment, taking into account their educational level and culture, because this could contribute to the process of promoting resilience in these patients. For this to occur, specialization courses are necessary so that these professionals can understand the process of resilience and develop techniques to promote it in patients with SLE.

Regarding the internal protective factors associated to promoting resilience, generally, studies in several populations have shown that a person triggers a resilience process when he presents a sense of self efficacy, sense of humour and has intellectual capacities such as the potential for insight [11], self esteem [34] and autonomy [12] along with the addition of self-care, the development of positive challenging and self defence strategies [15]. Living with SLE implies just adjusting to the complex dynamic among the changes in lifestyle and habits that can contribute to preventing the risk factors, adaption of routines and adhesion to medication, the implementation of care and treatments.

Thus it is important to promote resilience so that the patient accepts the limitations of the disease, develops positive mental attitudes [15] and protection factors [12], that even include the treatment [15]. For this, it is necessary to adopt a healthy lifestyle, including modification in diet, regular physical exercise, stress control and excess work control, avoiding events that may trigger or aggravate symptoms [15]. Psychological support can be a factor that can help to develop or enhance these characteristics. The implantation of support groups and psychological assistance groups would be important for patients with SLE, because one could attempt to develop in these patients individual potentialities that could help to promote resilience as is the case of self-esteem [12,15], self-care [15] and autonomy [12]. The literature also reports that some patients with SLE have found strength to face the disease in spiritual inspiration [15] that is therefore an important factor to be considered in the process of promoting resilience.

\section{CONCLUSION}

It was concluded that resilience provides a healthy way of living for the patient with SLE and allows him/her to adapt to the life style and incorporate therapeutic practices that involve alterations in daily behavior patterns. Patients with high resilience tended to carry out the treatment correctly, tried to understand the disease and had greater treatment adhesion to promote the protection factors, and managed to maintain their daily activities, even with the limitations of the disease. Therefore, it is necessary to develop mechanisms that help promote resilience in patients with SLE. For the population studied, it must be taken into account that their low educational level probably meant that they had difficulty in understanding the disease and their low purchasing power means that these patients depend solely on state aid, which is precarious in Brazil. State actions are needed to facilitate access to treatment, in addition to educational policies to improve understanding of the disease and the necessary treatments. Medical and family support are also described as fundamental to promote resilience. The internal aspects of the subject, such as the potential for insight, self-esteem, autonomy, self-care, development of positive reactive strategies and self-defense should also be considered for resilience promotion. Psychological support could help to develop these internal characteristics, contributing to promoting resilience and consequentially adhesion to treatment.

Limitation was cross-sectional presenting a cut of the sample studied. It is further emphasized that the sample number was small because of the requirements of the research inclusion criteria and that possible associations were not assessed between resilience and disease activity. Regarding the use of indices of disease activity such as SLEDAI, SLAM and the index of damage SLICC ACR-DI, unfortunately we could not apply them during the study due to operational issues of high demand of patients for outpatient care. That could be important data for the study of resilience linked to SLE, the subject of an intended future study. It is hoped that this study has gathered together information to increase knowledge of resilience in SLE patients, because there are very few studies on resilience and rheumatic diseases that limits comparison, mainly with results of studies from local populations, where there are specific studies yet on resilience and chronic patients of patients with SLE.

\section{CONFLICT OF INTEREST}

We declare that there is no conflict of interest.

\section{ACKNOWLEDGEMENTS}

The authors thank the UFRN Health Sciences Graduate Program in Health Sciences and the statistician Janiere Lira.

\section{REFERENCES}

[1] Daleboudt GM, Broadbent E, Berger SP, Kaptein AA. Illness perceptions in patients with systemic lupus erythematosus and proliferative lupus. Lupus 2011; 20(3): 290-8.

[2] Baker K, Pope J, Fortin P, Silverman E, Peschken C. Work disability in systemic lupus erythematosus is prevalent and associated with socio-demographic and disease related factors. Lupus 2009; 18(14): 1281-8.

[3] Kulczycka L, Sysa-Jedrzejowska A, Robak E. Life satisfaction together with positive and negative aspects in Polish patients with systemic lupus erythematosus. J Eur Acad Dermatol Venereol 2009; 23(3): 251-5.

[4] Carr FN, Nicassio PM, Ishimori ML, et al. Depression predicts self-reported disease activity in systemic lupus erythematosus. Lupus 2011; 20(1): 80-4.

[5] Philip EJ, Lindner MA, Lederman HL. Relationship of illness perceptions with depression among individuals diagnosed with lupus. J Depress Anxiety 2009; 26(6): 575-82.

[6] Lederman LF, Lindner H, Greenwood KM, et al. Depression and pain in night time and daytime functioning of individuals with lupus. Psychol Health 2008; 23(5): 537-50.

[7] Navarrete-Navarrete N, Peralta-Ramírez MI, Sabio JM, MartínezEgea I, Santos-Ruiz A, Jiménez-Alonso J. Quality-of-life predictor factors in patients with SLE and their modification after cognitive behavioural therapy. Lupus 2010; 19(14): 1632-9. 
[8] Reis MG, Costa IP. Qualidade de vida relacionada à saúde em pacientes com lúpus eritematoso sistêmico no Centro-Oeste do Brasil. Rev Bras Reumatol [serial on the Internet]. 2010 August; [cited 2013 September 30]; 50(4): 408-22. Available from www.scielo.br/ scielo.php?script=sci_arttext\&pid=S0482-50042010000400006\&ln g=en. http://dx.doi.org/10.1590/S0482-50042010000400006

[9] Vilar MJP, Rodrigues JM, Sato EI. Incidência de lúpus eritematoso sistêmico em Natal, RN - Brasil. Rev Bras Reumatol [serial on the Internet]. 2003 December; [cited 2014 January 02]; 43(6): 343-346. Available from http://www.scielo.br/scielo.php?script=sci_arttext\& pid=S0482-50042003000600005\&lng=en

[10] Oliveira MA, Reis VL, Zanelato LS, Neme CMB. Resiliência: Análise das Publicações no Período de 2000 a 2006. Psicol Cienc Prof [serial on the Internet]. 2008 December; [cited 2013 September 30]; 28(4): 754-67. Available from http://pepsic.bvsal ud.org/scielo.php?script=sci_arttext\&pid=S1414-98932008000400008

[11] Carvalho FT, Morais NA, Koller SH, Piccinini CA. Fatores de proteção relacionados à promoção de resiliência em pessoas que vivem com HIV/AIDS. Cad Saúde Pública [serial on the Internet]. 2007 September; [cited 2013 September 30]; 23(9): 2023-33. Available from http://www.scielo.br/scielo.php?script $=$ sci_arttext\& pid $=$ S0102-311X2007000900011\&lng=en\&nrm=iso\&tlng=pt

[12] Ferreira CL, Santos LMO, Maia EMC. Resiliência em idosos atendidos na rede de atenção básica de saúde em município do nordeste brasileiro. Rev Esc Enferm USP [serial on the Internet]. 2012 April; [cited 2013 September 30]; 46(2): 328-34. Available from http://www.scielo.br/scielo.php?script=sci_arttext\&pid=S008 0-62342012000200009

[13] Poletto M, Koller SH. Contextos ecológicos: promotores de resiliência, fatores de risco e de proteção. Estud psicol (Campinas) [serial on the Internet]. 2008 September; [cited 2013 September 30]; 25(3): 405-16. Available from http://www.scielo.br/scielo.ph p?script $=$ sci_arttext\&pid $=$ S0103-166X2008000300009\&lng=en\&n $\mathrm{rm}=\mathrm{iso} \& \mathrm{t} \operatorname{lng}=\mathrm{pt}$

[14] Bianchini DCS, Dell'Aglio DD. Processos de resiliência no contexto de hospitalização: um estudo de caso. Paidéia [serial on the Internet]. 2006 February; [cited 2014 January 02]; 16(35): 427436. Available from http://www.scielo.br/pdf/paideia/v16n35/v16n 35a13.pdf

[15] Sutanto B, Singh-Grewal D, McNeil HP. et al. Experiences and perspectives of adults living with systemic lupus erythematosus: thematic synthesis of qualitative studies. Arthritis Care Res 2013; 65(11): 1752-65.

[16] Borba EF, Latorre LC, Brenol JCT, et al. Consenso de Lúpus Eritematoso Sistêmico. Rev Bras Reumatol [serial on the Internet]. 2008 August; [cited 2013 September 30]; 48(4): 196-207. Available from http://www.scielo.br/scielo.php?script=sci_arttext\& pid=S0482-50042008000400002\&lang=pt

[17] Wagnild GM, Young HM. Development and psychometric evaluation of the Resilience Scale. Research Support, Non-U.S. Gov't. Journal of Nursing Measurement 1993; 1:165-178.

[18] Pesce RP, Assis SG, Avanci JQ, et al. Adaptação transcultural, confiabilidade e validade da escala de resiliência. Cad Saúde Pública [serial on the Internet]. 2005 April; [cited 2013 September 30]; 21(2): 436-48. Available from http://www.scielo.br/scielo.ph p?pid $=$ S0102-311X2005000200010\&script $=$ sci_arttext

[19] Baker K, Pope J. Employment and work disability in systemic lupus erythematosus: a systematic review. Rheumatology (Oxford) [serial on the Internet]. 2009 January; [cited 2013 September 30]; 48(3): 281-4. Available from http://rheumatology.oxfordjournals. org/content/48/3/281.full.pdf + html
[20] Robinson DJ, Aguilar D, Schoenwetter M. et al. Impact of systemic lupus erythematosus on health, family, and work: The patient perspective. Arthritis Care Res (Hoboken) [serial on the Internet]. 2010 February; [cited 2013 September 30]; 62(2): 26673. Available from http://onlinelibrary.wiley.com/doi/10.1002/acr. 20077/pdf

[21] Araújo AD, Traverso-Yépez MA. Expressões e sentidos do lúpus eritematoso sistêmico. Estud de Psicol [serial on the Internet]. 2007 August; [cited 2013 September 30]; 12(2): 119-27. Available from http://www.scielo.br/scielo.php?pid=S1413-

294X2007000200003\&script $=$ sci arttext

[22] Aberer E. Epidemiologic, socioeconomic and psychosocial aspects in lupus erythematosus. Lupus 2010; 19(9): 1118-24.

[23] Cal SF, Santiago MB. Resilience in systemic lupus erythematosus. Psychol Health Med 2013; 18(5): 558-63.

[24] Wagnild GM, Collins JA. Assessing resilience. J Psychosoc Nurs Ment Health Serv 2009; 47(12): 28-33.

[25] Julian LJ, Yelin E, Yazdany J, et al. Depression, medication adherence, and service utilization in systemic lupus erythematosus. Arthritis Rheuma [serial on the Internet]. 2009 February; [cited 2013 September 30]; 61(2): 240-6. Available from http://www. ncbi.nlm.nih.gov/pmc/articles/PMC2875189/pdf/nihms138455.pdf

[26] Oliveira-Santos M, Verani JFS, Klumb EM, Albuquerque EM. Evaluation of adherence to drug treatment in patients with systemic lupus erythematosus in Brazil. Lupus 2011; 20(3): 320-9.

[27] Garcia-Gonzalez A, Richardson M, Popa-Lisseanu MG, et al. Treatment adherence in patients with rheumatoid arthritis and systemic lupus erythematosus. Clin Rheumatol 2008; 27(7): 883-9.

[28] Jarpa E, Babul M, Calderon J, et al. Common mental disorders and psychological distress in systemic lupus erythematosus are not associated with disease activity. Lupus 2011; 20(1): 58-66.

[29] Bachen EA, Chesney MA, Criswell LA. Prevalence of mood and anxiety disorders in women with systemic lupus erythematosus. Arthritis Rheum [serial on the Internet]. 2009 June; [cited 2013 September 30]; 61(6): 822-9. Available from http://www.ncbi.nlm. nih.gov/pmc/articles/PMC2763591/

[30] White-Koning M, Bertozzi-Salamon AI, Vignes M, Arnold C. Compliance to treatment of adolescents with cancer. Bull Cancer [serial on the Internet]. 2007 April; [cited 2013 September 30]; 94(4): 349-56. Available from http://www.jle.com/e-docs/00/04/2 E/8D/vers_alt/VersionPDF.pdf

[31] Lundman B, Strandberg C, Eisemann M, Gustafson Y, Brulin C. Psychometric properties of the swedish version of the resilience scale. Scand J Caring Sci 2007; 21(2): 229-37.

[32] Rodrigues FS, Polidori MM. Enfrentamento e Resiliência de Pacientes em Tratamento Quimioterápico e seus Familiares. Rev Bras Cancerologia [serial on the Internet]. 2012 August; [cited 2013 December 15]; 58(4): 619-627. Available from http://www.inca.gov.br/rbc/n_58/v04/pdf/07-artigo-enfrentamentoresiliencia-pacientes-tratamento-quimioterapico-familiares.pdf

[33] Yunes MAM. Psicologia positiva e resiliência: o foco no indivíduo e na família. Psicol Estud [serial on the Internet]. 2003 June; [cited 2013 December 15]; 8: 75-84. Available from http://www.scielo.br/ scielo.php?script $=$ sci_arttext\&pid $=$ S1413-73722003000300010\&ln $\mathrm{g}=$ en\&tlng=pt. 10.1590/S1413-73722003000300010

[34] Tavares BC, Barreto FA, Lodetti M L, Silva DMGV, Lessmann JC. Resiliência de pessoas com Diabetes Mellitus. Texto contexto enferm. [serial on the Internet]. 2011 December; [cited 2013 December 12]; 20(4): 751-757. Available from http://www.scielo.b r/scielo.php?script $=$ sci_arttext\&pid $=$ S010407072011000400014\&lng=en. http://dx.doi.org/10.1590/S010407072011000400014 